ARTICLE

https://doi.org/10.1038/s41467-018-07678-w

\title{
Efficient oxygen evolution electrocatalysis in acid by a perovskite with face-sharing $\mathrm{IrO}_{6}$ octahedral dimers
}

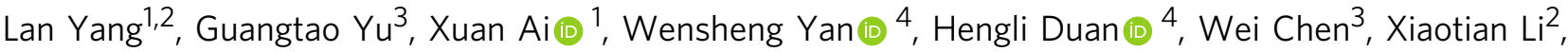 \\ Ting Wang ${ }^{3}$, Chenghui Zhang ${ }^{3}$, Xuri Huang ${ }^{3}$, Jie-Sheng Chen $^{5} \&$ Xiaoxin Zou (1) ${ }^{1}$
}

The widespread use of proton exchange membrane water electrolysis requires the development of more efficient electrocatalysts containing reduced amounts of expensive iridium for the oxygen evolution reaction (OER). Here we present the identification of $6 \mathrm{H}$-phase $\mathrm{SrlrO}_{3}$ perovskite $\left(6 \mathrm{H}-\mathrm{SrlrO}_{3}\right)$ as a highly active electrocatalyst with good structural and catalytic stability for OER in acid. $6 \mathrm{H}-\mathrm{SrlrO}_{3}$ contains $27.1 \mathrm{wt} \%$ less iridium than $\mathrm{IrO}_{2}$, but its iridium mass activity is about 7 times higher than $\mathrm{IrO}_{2}$, a benchmark electrocatalyst for the acidic OER. $6 \mathrm{H}-\mathrm{SrlrO}_{3}$ is the most active catalytic material for OER among the iridium-based oxides reported recently, based on its highest iridium mass activity. Theoretical calculations indicate that the existence of face-sharing octahedral dimers is mainly responsible for the superior activity of $6 \mathrm{H}-\mathrm{SrlrO}_{3}$ thanks to the weakened surface $\mathrm{Ir}-\mathrm{O}$ binding that facilitates the potential-determining step involved in the OER (i.e., $\mathrm{O}^{*}+\mathrm{H}_{2} \mathrm{O} \rightarrow \mathrm{HOO}^{\star}+\mathrm{H}^{+}+$e-).

\footnotetext{
${ }^{1}$ State Key Laboratory of Inorganic Synthesis and Preparative Chemistry, College of Chemistry, Jilin University, 130012 Changchun, People's Republic of China. ${ }^{2}$ College of Materials Science and Engineering, Jilin University, 130022 Changchun, People's Republic of China. ${ }^{3}$ Laboratory of Theoretical and Computational Chemistry, Institute of Theoretical Chemistry, Jilin University, 130023 Changchun, People's Republic of China. ${ }^{4}$ National Synchrotron Radiation Laboratory, University of Science and Technology of China, 230029 Hefei, Anhui, People's Republic of China. ${ }^{5}$ School of Chemistry and Chemical Engineering, Shanghai Jiao Tong University, 200240 Shanghai, People's Republic of China. These authors contributed equally: Lan Yang, Guangtao Yu. Correspondence and requests for materials should be addressed to W.C. (email: w_chen@jlu.edu.cn) or to X.Z. (email: xxzou@jlu.edu.cn)
} 
T he oxygen evolution reaction (OER) is the primary reaction that occurs at the anode in many electrochemical energy conversion processes, such as water splitting, $\mathrm{CO}_{2}$ reduction, $\mathrm{N}_{2}$ fixation, etc ${ }^{1-3}$. Due to its multi-proton/electroncoupled kinetics, the OER is a quite sluggish half-reaction, and often has a crucial role in the overall efficiency of these electrochemical processes ${ }^{1,4,5}$. Therefore, over the past several years, considerable effort has been devoted to the search and synthesis of efficient electrocatalysts that can significantly lower the kinetic barriers for OER. Whereas a large number of oxygen evolution electrocatalysts based on a wide range of transition metals work well under alkaline conditions $s^{6-13}$, only the few of the recently developed electrocatalysts are found to be effective for OER in acidic media ${ }^{14-23}$. Despite the difficulties, there are strong demands for the OER in acidic $\mathrm{pH}$ regime. For instance, proton exchange membrane (PEM) water electrolysis is an attractive and advanced route for sustainable hydrogen production ${ }^{24}$, especially when coupled with some renewable energy systems. PEM water electrolysis offers many advantages, such as high current densities, ultrahigh gas purities, low ohmic losses and good compactness $^{24}$. But this technique requires corrosion-resistant electrocatalysts that can operate efficiently in strongly acidic media.

The reasons for the slow development of OER electrocatalysts operating in acid can be reflected by the facts that: first, the great majority of promising electrocatalysts, including those can work well in alkaline media, are chemically unstable in acid ${ }^{6-13}$; second, the corrosion/decomposition of electrocatalysts in acid always get worse under a strongly oxidative electrocatalysis condition; third, even for the few with relatively good catalytic stability in acid, uncontrolled surface reconstruction often take place during electrocatalysis, so that the accurate elucidation of the atomic basis for catalytic properties is very difficult ${ }^{16,17}$. At present, iridium-based oxides, especially $\mathrm{IrO}_{2}$, are generally considered the only electrocatalysts with reasonable activity and stability for the acidic OER. So, considering the high cost and low
Earth abundance of iridium, researchers are in pursuit of corrosion-resistant, structurally stable, more active oxygen evolution electrocatalysts containing reduced iridium amount.

Herein we identify $6 \mathrm{H}-\mathrm{SrIrO}_{3}$, containing $27.1 \mathrm{wt} \%$ less iridium than $\mathrm{IrO}_{2}$, as a highly efficient electrocatalyst with excellent structural stability for OER in acid. The material gives the lowest overpotential at $10 \mathrm{~mA} \mathrm{~cm}_{\text {geo }}{ }^{-2}$ (current densities per geometric area), and exhibits the highest iridium mass activity for the acidic OER among the iridium-based oxide catalysts reported recently. To the best of our knowledge, an iridium-based compound (or an unusual perovskite oxide) with face-sharing $\mathrm{IrO}_{6}$ octahedral subunits has never been reported to effectively electrocatalyze OER in acid. In addition, $6 \mathrm{H}-\mathrm{SrIrO}_{3}$ has never been studied as a catalyst in any chemical reactions.

\section{Results}

Crystal structure and electrical conductivity of $6 \mathrm{H}-\mathrm{SrIrO}_{3} .6 \mathrm{H}-$ $\mathrm{SrIrO}_{3}$ is the thermodynamically stable polymorph of $\mathrm{SrIrO}_{3}$, and adopts a monoclinic distortion structure of the hexagonal form of perovskite $\mathrm{BaTiO}_{3}$ (Fig. 1a) ${ }^{25}$. It consists of alternating facesharing $\mathrm{IrO}_{6}$ octahedral dimers and corner-sharing, isolated $\mathrm{IrO}_{6}$ octahedra along the $c$ axis (Fig. 1b). Correspondingly, there are two types of Ir atoms in $6 \mathrm{H}-\mathrm{SrIrO}_{3}$. One is in the face-sharing $\mathrm{IrO}_{6}$ octahedral dimers, and the other is in the corner-sharing, isolated $\mathrm{IrO}_{6}$ octahedra (Fig. 1c). It is remarkable that there is $\mathrm{Ir}-\mathrm{Ir}$ metallic bonding in face-sharing $\mathrm{IrO}_{6}$ octahedra, as revealed by the very short $\operatorname{Ir}(\mathrm{I})-\operatorname{Ir}(\mathrm{I})$ distance $(2.796 \AA)$. This can be further supported by the electron location function $(E L F)^{26,27}$. As presented in Fig. 1d, the correlative ELF values with a range of 0.4 to 0.5 distribute between the two neighboring Ir atoms in facesharing $\mathrm{IrO}_{6}$ dimers, indicating that $\mathrm{Ir}-\mathrm{Ir}$ bond is metallic in character. (See details about ELF in Methods). Besides Ir-Ir metallic bonding, there are obviously weaker Ir-O bonds in the face-sharing $\mathrm{IrO}_{6}$ octahedral dimers in comparison with those in the corner-sharing, isolated $\mathrm{IrO}_{6}$ octahedra. As shown in Fig. 1c
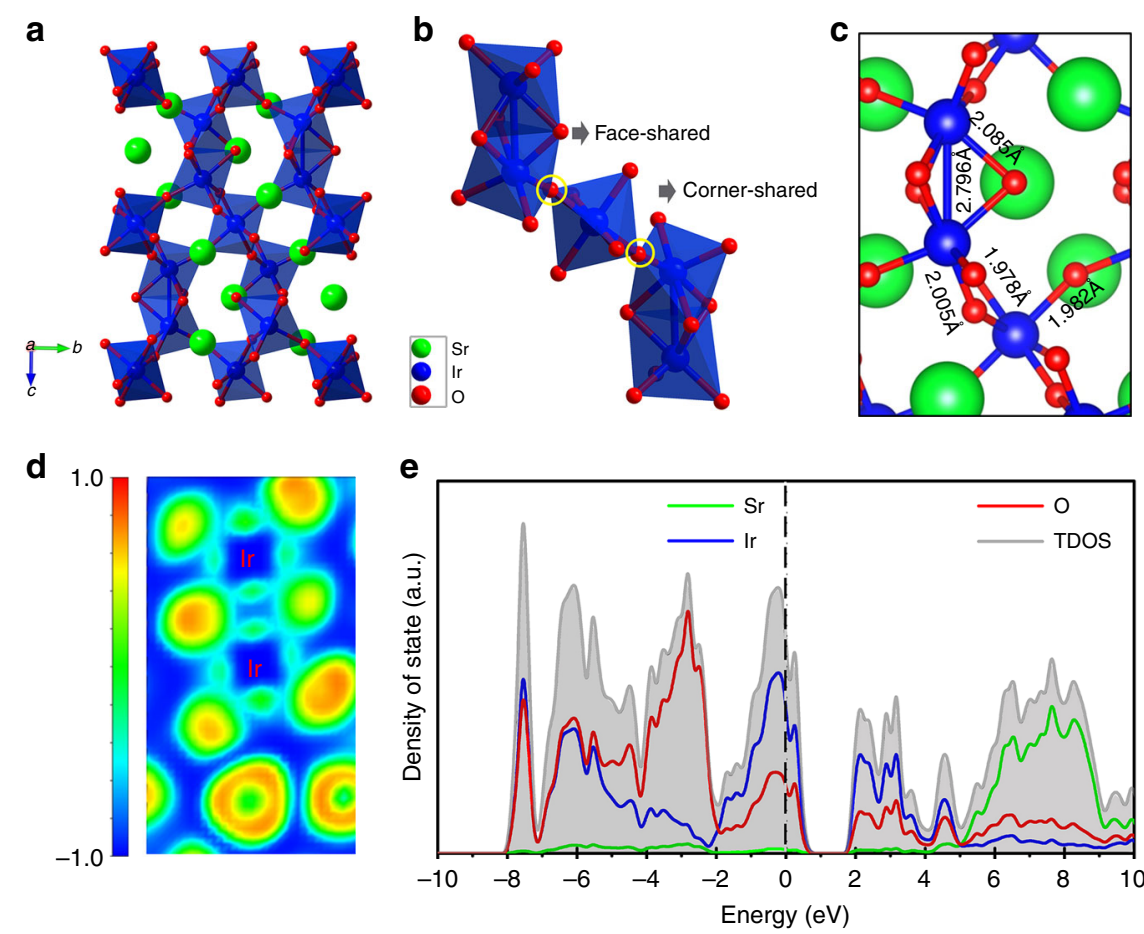

Fig. $1 \mathrm{Crystal}$ structure and electronic structure of $6 \mathrm{H}-\mathrm{SrlrO}_{3}$. a Crystal structure of $6 \mathrm{H}-\mathrm{SrlrO}_{3}$. b A local connection pattern of IrO $\mathrm{O}_{6}$ octahedra, in which face-sharing $\mathrm{IrO}_{6}$ octahedral dimers and corner-sharing, isolated $\mathrm{IrO}_{6}$ octahedron are shown. c Local ball-and-stick model of $6 \mathrm{H}$-SrlrO${ }_{3}$, in which typical Ir-Ir and Ir-O bond lengths are presented. d Plot of electron location function for Ir-Ir bonding in $6 \mathrm{H}_{-} \mathrm{SrlrO}_{3}$. e Density of states of $6 \mathrm{H}-\mathrm{SrlrO} \mathrm{O}_{3}$, in which the Fermi level is $0 \mathrm{eV}$ 

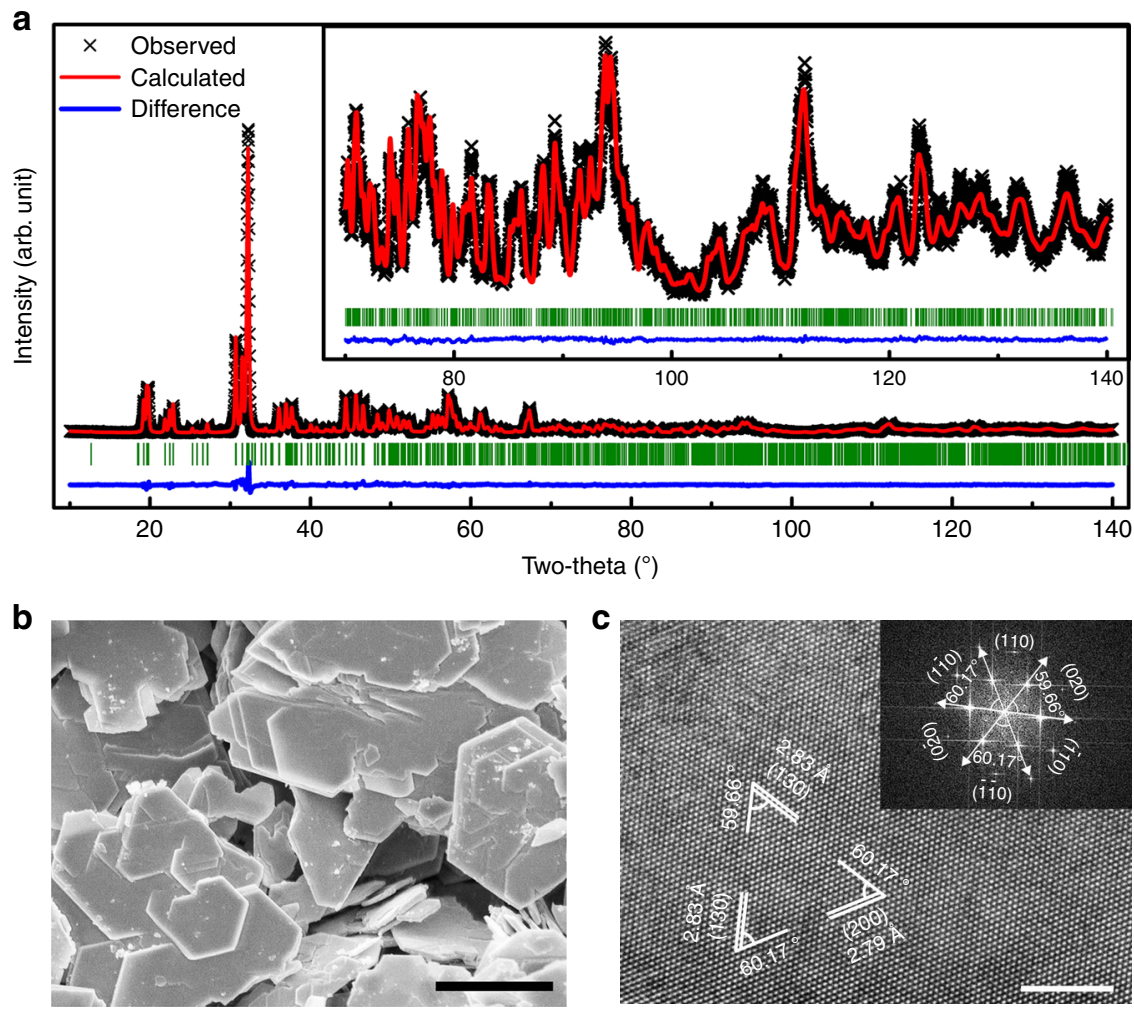

Fig. 2 Structural characterizations of $6 \mathrm{H}-\mathrm{SrlrO}_{3} . \mathbf{a}, \mathrm{XRD}$ pattern with a refinement plot of $6 \mathrm{H}-\mathrm{SrlrO}_{3} . \mathbf{b}, \mathrm{SEM}$ image of $6 \mathrm{H}-\mathrm{SrlrO} \mathrm{O}_{3} . \mathrm{Scale}$ bar, $2 \mu \mathrm{m}$. c, $\mathrm{HRTEM}$ image of $6 \mathrm{H}-\mathrm{SrlrO}_{3}$. Scale bar, $5 \mathrm{~nm}$. Inset: the corresponding fast Fourier transform image

and Supplementary Figure 1, the Ir-O bond lengths in the former, ranging from 2.005 to $2.085 \AA$, are much larger than those in the latter (1.978-1.982 $\AA$, close to those in $\left.\mathrm{IrO}_{2}\right)$. The face-sharing $\mathrm{IrO}_{6}$ octahedra and the unique bonding features in them, including the $\mathrm{Ir}-\mathrm{Ir}$ metallic bonding and the weak $\mathrm{Ir}-\mathrm{O}$ bonding, mark $6 \mathrm{H}-\mathrm{SrIrO}_{3}$ off from other Ir-based oxide catalysts reported previously (e.g., $\mathrm{IrO}_{2}$, see its crystal structure in Supplementary Figure 2) ${ }^{15-22}$.

The computed density of state (DOS) for $6 \mathrm{H}-\mathrm{SrIrO}_{3}$ reveals that this material has intrinsic metallic conductivity ${ }^{25,28}$, which is reflected by the density of state from $\mathrm{Ir}$ and $\mathrm{O}$ atoms crossing the Fermi level (Fig. 1e). This is further supported by the experimental result (Supplementary Figure 3). The electrical resistivity of $6 \mathrm{H}-\mathrm{SrIrO}_{3}$ was measured to be $\sim 2.7 \times 10^{-4} \Omega \mathrm{m}$ at room temperature. The metallic conductivity of $6 \mathrm{H}-\mathrm{SrIrO}_{3}$ is believed to be beneficial for electrochemical applications.

Synthesis and electrochemical properties for OER in acid of $6 \mathrm{H}-\mathrm{SrIrO}_{3}$. Encouraged by the unique crystal structure of $6 \mathrm{H}-$ $\mathrm{SrIrO}_{3}$, we synthesized this material and attempted to explore its potential electrocatalytic activity for OER in acid. The observed powder X-ray diffraction (XRD) pattern is almost in agreement with the fitting plot (Fig. 2a), revealing that the material is composed of high purity $6 \mathrm{H}-\mathrm{SrIrO}_{3}$. The refinement results are listed in Supplementary Table 1. Scanning electron microscopy (SEM) images (Fig. 2b and Supplementary Figure 4) show that the material has micron-sized, plate-like particles with a dominant thickness distribution of $30-60 \mathrm{~nm}$. Additionally, chemical mapping and energy dispersive X-ray spectroscopy (EDS) show that the $\mathrm{Sr}$ and Ir elements are homogeneously distributed over the material, with a Sr:Ir atomic ratio of ca. 1:1 (Supplementary Figure 5). X-ray photoelectron spectroscopy (XPS) result further reveals a Sr:Ir atomic ratio of ca. 1:1 for $6 \mathrm{H}-\mathrm{SrIrO}_{3}$. In the high resolution transmission electron microscopy (HRTEM) images
(Fig. 2c and Supplementary Figure 6), three sets of lattice fringes are shown, giving interplanar distances of $0.283,0.279$, and 0.283 $\mathrm{nm}$ corresponding to the (130), (200), and (130) crystallographic planes of $6 \mathrm{H}-\mathrm{SrIrO}_{3}$, respectively. The observed angles between these crystallographic planes match well with the theoretical values. These results further suggest that the exposed facet of micron-sized $6 \mathrm{H}-\mathrm{SrIrO}_{3}$ plates is $\{001\}$. The exposure of this facet is also confirmed by the fast Fourier transform image (Fig. 2c, inset). Furthermore, high-angle annular dark field (HAADF) STEM image (Supplementary Figure 7) of the edge of a $6 \mathrm{H}-\mathrm{SrIrO}_{3}$ particle again reveals that the $6 \mathrm{H}-\mathrm{SrIrO}_{3}$ is highly crystalline.

Before the electrocatalytic studies, we first tested the chemical stability of $6 \mathrm{H}-\mathrm{SrIrO}_{3}$ in strongly acidic media $\left(0.5 \mathrm{M} \mathrm{H}_{2} \mathrm{SO}_{4}\right)$. $\mathrm{XRD}$ and TEM results reveal that $6 \mathrm{H}-\mathrm{SrIrO}_{3}$ retains its crystal structure well, even after its exposure in $0.5 \mathrm{M} \mathrm{H}_{2} \mathrm{SO}_{4}$ over 48 days (Supplementary Figure 8). In addition, after such a long time testing, there is no detectable leached Ir species and only $\sim 1.3 \%$ of total $\mathrm{Sr}$ content leached in the acidic solution. These results suggest that $6 \mathrm{H}-\mathrm{SrIrO}_{3}$ has excellent chemical stability in acid.

Next, we evaluated the electrocatalytic properties of $6 \mathrm{H}-\mathrm{SrIrO}_{3}$ toward OER in acidic media $\left(0.5 \mathrm{M} \mathrm{H}_{2} \mathrm{SO}_{4}\right)$. For comparative purpose, we also synthesized $\mathrm{IrO}_{2}$ nanoparticles with a particle size of 10-20 nm (see structural characterizations in Supplementary Figure 9) and studied their catalytic activity for OER. As shown in Fig. 3a, both $6 \mathrm{H}-\mathrm{SrIrO}_{3}$ and $\mathrm{IrO}_{2}$ exhibit remarkable electrocatalytic activity toward OER, and the former is more active than the latter. For example, at $1.525 \mathrm{~V}$, the electrocatalytic activity of $6 \mathrm{H}-\mathrm{SrIrO}_{3}$ (measured by the current densities per the geometric area) is almost four times higher than that of $\mathrm{IrO}_{2}$. Additionally, $6 \mathrm{H}-\mathrm{SrIrO}_{3}$ produces a current density of $10 \mathrm{~mA} \mathrm{~cm}^{-2}$ geo at an overpotential $(\eta)$ of $248 \mathrm{mV}$, whereas $\mathrm{IrO}_{2}$ gives the same current density at a higher overpotential $(300 \mathrm{mV})$. The results also reveal that $6 \mathrm{H}-\mathrm{SrIrO}_{3}$ is among 
a Overpotential $\eta(\mathrm{V})$
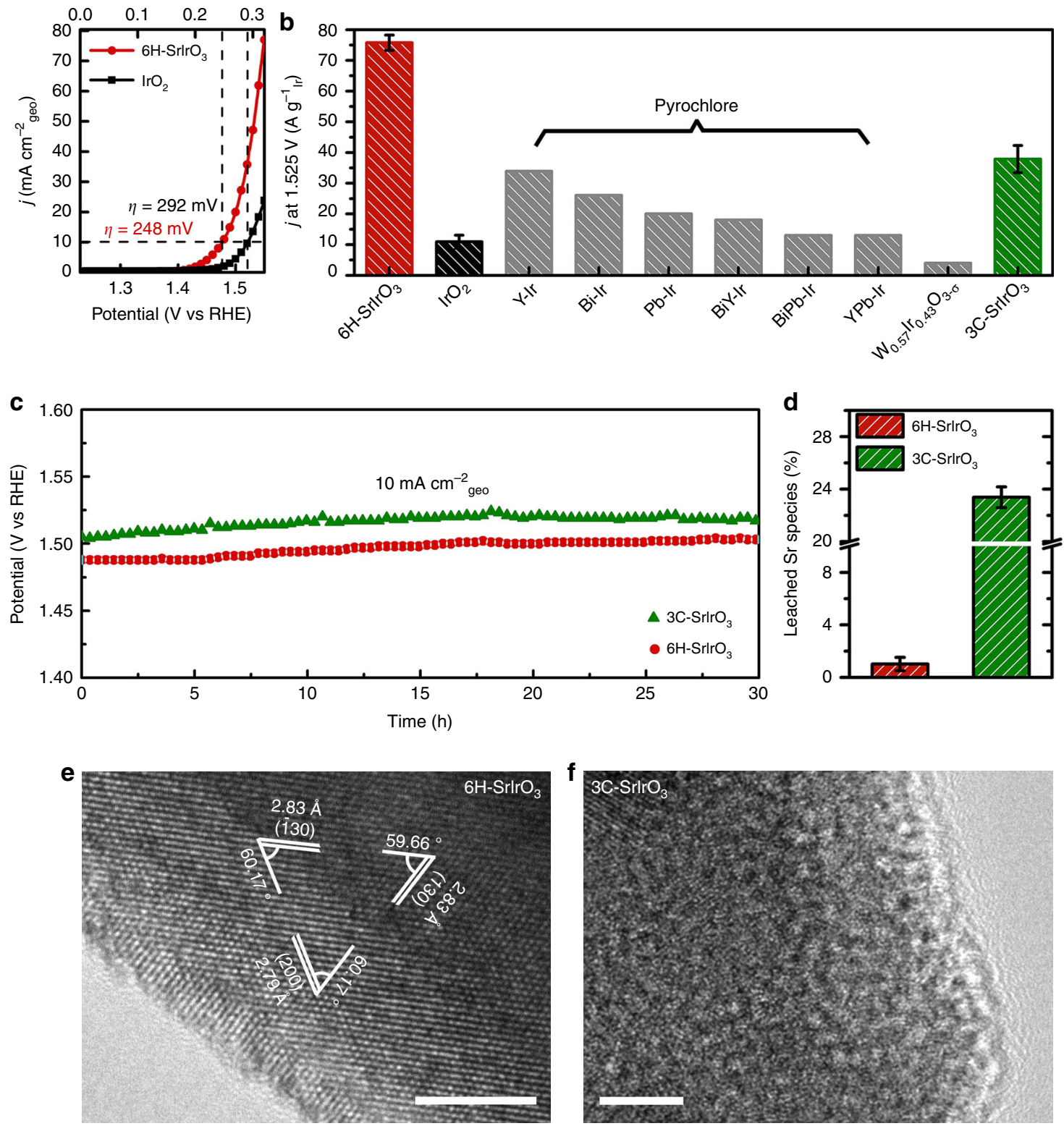

Fig. 3 Electrocatalytic properties for OER of $6 \mathrm{H}-\mathrm{SrlrO}_{3}$. a Polarization curves of $6 \mathrm{H}-\mathrm{SrlrO}_{3}$ and $\mathrm{IrO}_{2}$ in $0.5 \mathrm{M} \mathrm{H}_{2} \mathrm{SO}_{4}$ solution with $85 \%$ iR-compensations. The current densities are normalized by the geometric area. b Comparison of mass activity, normalized by the mass of iridium at $1.525 \mathrm{~V}$ vs. RHE, of $6 \mathrm{H}-\mathrm{SrlrO}_{3}, \mathrm{IrO}_{2}, 3 \mathrm{C}$-SrlrO 3 , and some Ir-containing catalysts reported recently. The error bar represents standard deviation based on five measurements. c Chronopotentiometric curves for OER in the presence of $6 \mathrm{H}-\mathrm{SrlrO}_{3}$ and $3 \mathrm{C}-\mathrm{SrlrO}_{3}$ in $0.5 \mathrm{M} \mathrm{H}_{2} \mathrm{SO}_{4}$ solution at $10 \mathrm{~mA} \mathrm{~cm}^{-2}$ geo (without iR compensations). d Percentage of total $\mathrm{Sr}$ content leached (or deviated from the stoichiometry) in the solution after $30 \mathrm{~h}$-long catalytic stability test in the presence of $6 \mathrm{H}-\mathrm{SrlrO}_{3}$ and $3 \mathrm{C}-\mathrm{SrlrO}_{3}$. e, $\mathbf{f} \mathrm{HRTEM}$ images for $6 \mathrm{H}-\mathrm{SrlrO}_{3}$ and $3 \mathrm{C}-\mathrm{SrlrO}_{3}$ after 30 h-long catalytic stability test. Scale bars, $5 \mathrm{~nm}$

the most active Ir-based oxide electrocatalysts for OER in acid (see Supplementary Table 2), although there might be the differences in protocols, such as catalyst loading, use of binder and electrolyte, employed in their electrocatalytic tests. For example, some $\mathrm{Pb}-, \mathrm{Bi}-$, or $\mathrm{Y}$-containing, $\mathrm{Ir}$-based pyroclore compounds usually give a current density of $10 \mathrm{~mA} \mathrm{~cm}^{-2}$ geo at overpotantials higher than $340 \mathrm{mV}^{19-22}$, and $\mathrm{Ir}-\mathrm{W}$ bimetallic oxide catalysts with an optimal composition require an overpotential of $370 \mathrm{mV}$ for the acidic OER ${ }^{22}$. Moreover, a perovskitetype $\mathrm{La}_{2} \mathrm{LiIrO}_{6}$ catalyst can produce a current density of $10 \mathrm{~mA}$ $\mathrm{cm}^{-2}$ geo at an overpotential of ca. $300 \mathrm{mV}^{17}$, but this material suffers from the serious surface reconstruction, resulting in the generation of $\mathrm{IrO}_{2}$ nanoparticles, during electrocatalysis.
Besides exhibiting good catalytic activity per geometric area, $6 \mathrm{H}-\mathrm{SrIrO}_{3}$ also shows good mass activity (normalized by the mass of iridium) for the acidic OER. As shown in Fig. 3b, 6H-SrIrO gives the highest mass activity for OER in acid among the iridium-based oxide electrocatalysts reported recently $15,16,18-22$ The mass activity of $6 \mathrm{H}-\mathrm{SrIrO}_{3}$ is about seven times as high as that of $\mathrm{IrO}_{2}$, and is 2.2-5.8 times higher than those of Ir-based pyroclore compounds. The mass activity of $6 \mathrm{H}-\mathrm{SrIrO}_{3}$ is even around twenty times higher than the Ir-W bimetallic oxide catalyst. Moreover, it is worth noting that the superior catalytic activity of $6 \mathrm{H}-\mathrm{SrIrO}_{3}$ does not correlate with its surface area. The surface area (obtained with $\mathrm{N}_{2}$ adsorption method) of $6 \mathrm{H}-\mathrm{SrIrO}_{3}$ is typically lower by more than an order of magnitude in 
comparison with the Ir-based catalysts mentioned above (see Supplementary Table 2). For example, the $\mathrm{IrO}_{2}$ sample has a larger BET surface area $\left(19.8 \mathrm{~m}^{2} \mathrm{~g}^{-1}\right)$ than $6 \mathrm{H}-\mathrm{SrIrO}_{3}$, due to the former's smaller particle size (see Supplementary Figures 4 and 9). This is in agreement with the effective electrochemical active surface area of $\mathrm{IrO}_{2}$, which is measured to be about three times larger than that of $6 \mathrm{H}-\mathrm{SrIrO}_{3}$ (Supplementary Figure 10).

Comparison of electrocatalytic properties for OER between $\mathbf{6} \mathrm{H}-\mathrm{SrIrO}_{3}$ and $3 \mathrm{C}-\mathrm{SrIrO}_{3}$. In order to further assess the catalytic properties of $6 \mathrm{H}-\mathrm{SrIrO}_{3}$, we synthesized 3C-phase $\mathrm{SrIrO}_{3}$ perovskite $\left(3 \mathrm{C}-\mathrm{SrIrO}_{3}\right)$ as a reference material for comparative studies. $3 \mathrm{C}-\mathrm{SrIrO}_{3}$ adopts a well-known pseudo-cubic structure, in which all the $\mathrm{IrO}_{6}$ octahedra are corner-shared (see its crystal structure in Supplementary Figure 11) ${ }^{29}$. Additionally, the thinfilms of $3 \mathrm{C}-\mathrm{SrIrO}_{3}$ were recently demonstrated to give the best intrinsic catalytic activity for OER in acid ${ }^{16}$, due to the in situ generation of amorphous $\mathrm{IrO}_{\mathrm{x}}$ on the surface by serious strontium leaching during electrocatalysis.

The experimental procedures are almost the same for the synthesis of $6 \mathrm{H}-\mathrm{SrIrO}_{3}$ and $3 \mathrm{C}-\mathrm{SrIrO}_{3}$ (see experimental details in Methods). In order to explore the reasons why the addition of more critic acid in the synthesis can favor the formation of metastable $3 \mathrm{C}-\mathrm{SrIrO}_{3}$ over $6 \mathrm{H}-\mathrm{SrIrO}_{3}$, we first compared the Ir4f XPS spectra of $\mathrm{IrO}_{2}, 6 \mathrm{H}-\mathrm{SrIrO}_{3}$ and $3 \mathrm{C}-\mathrm{SrIrO}_{3}$ (Supplementary Figure 12a). The results reveal that the Ir $4 f_{5 / 2}$ and $\mathrm{Ir} 4 f_{7 / 2}$ XPS peaks for $3 \mathrm{C}-\mathrm{SrIrO}_{3}$ appear at the higher binding energies compared with $\mathrm{IrO}_{2}$ and $6 \mathrm{H}-\mathrm{SrIrO}_{3}$. This demonstrates that the average oxidation state of iridium for $3 \mathrm{C}-\mathrm{SrIrO}_{3}$ is higher than $4+{ }^{30}$. The higher average oxidation state of iridium are believed to be favorable for the formation of $3 \mathrm{C}-\mathrm{SrIrO}_{3}$. This argument is mainly based on recent studies, in which low-valent heteroatom doping (e.g., $\mathrm{Co}, \mathrm{Mg}, \mathrm{Zn}$, etc.) can lead to the increase in the oxidation state of iridium and the stabilization of $3 \mathrm{C}-\mathrm{SrIrO}_{3}{ }^{28,31,32}$. In view of the difference in synthetic systems between our work and the previous studies $28,31,32$, we attempted to synthesize $3 \mathrm{C}$-phase $\mathrm{SrIrO}_{3}$ by low-valent heteroatom doping (cobalt as dopants used in this work) with the experimental procedures that were used for the synthesis of $6 \mathrm{H}-\mathrm{SrIrO}_{3}$ (see experimental details in Methods). The results show that in this case, the formation of the 3C-phase is indeed preferable, and the resulting material also has a higher oxidation state of iridium (Supplementary Figure 12b). Next, we compared the thermogravimetric (TG) and differential thermal analysis (DTA) in air of the precursors of $6 \mathrm{H}-\mathrm{SrIrO}_{3}$ and $3 \mathrm{C}-\mathrm{SrIrO}_{3}$. As shown in Supplementary Figure 13a, the organic components in the precursors are oxidatively decomposed in air at elevated temperature (ca. $500{ }^{\circ} \mathrm{C}$ ), and this process is highly exothermic. The presence of more critic acid (i.e., the precursor for the synthesis of $3 \mathrm{C}-\mathrm{SrIrO}_{3}$ ) is also found to result in more heat released at elevated temperature. The more released heat in the synthesis should favor the generation of high-valent iridium species. This is confirmed by the XPS results (Supplementary Figure 13b), which show that the sample obtained by calcining the precursor of $6 \mathrm{H}-\mathrm{SrIrO}_{3}$ at $500{ }^{\circ} \mathrm{C}$ contains zero-valent and four-valent Ir species, whereas the sample obtained by calcining the precursor of $3 \mathrm{C}-\mathrm{SrIrO}_{3}$ at $500{ }^{\circ} \mathrm{C}$ contains four-valent and fivevalent Ir species. Overall, the presence of more critic acid favors the formation of $3 \mathrm{C}-\mathrm{SrIrO}_{3}$ by facilitating the generation of the more oxidized iridium species.

The $3 \mathrm{C}-\mathrm{SrIrO}_{3}$ material we synthesize contains of micronsized particles with a small surface area comparable with that of $6 \mathrm{H}-\mathrm{SrIrO}_{3}$ (Supplementary Figures 14, 15 and Table 2). The $3 \mathrm{C}-\mathrm{SrIrO}_{3}$ material has a Sr:Ir atomic ratio of $0.82: 1$ and a certain amount of $\mathrm{IrO}_{\mathrm{x}}$ on the surface. The Sr deficiency for
$3 \mathrm{C}-\mathrm{SrIrO}_{3}$ is because the acid treatment is necessary for the removal of the $\mathrm{SrCO}_{3}$ impurities during the material synthesis, and simultaneously, the acid treatment also results in some strontium leached from $3 \mathrm{C}-\mathrm{SrIrO}_{3}$. This result is also in agreement with the previous study showing the easy strontium leaching of $3 \mathrm{C}-\mathrm{SrIrO}_{3}$ in acid ${ }^{16}$.

The electrocatalytic result (Supplementary Figure 16) reveals that $3 \mathrm{C}-\mathrm{SrIrO}_{3}$ affords a current density of $10 \mathrm{~mA} \mathrm{~cm}^{-2}$ geo at an overpotential $(\eta)$ of $\sim 270 \mathrm{mV}$, which is similar to that $(270-290$ $\mathrm{mV})$ required by the thin films of $3 \mathrm{C}-\mathrm{SrIrO}_{3}$ reported previsouly ${ }^{16}$. Obviously, $6 \mathrm{H}-\mathrm{SrIrO}_{3}$ has a higher catalytic activity than $3 \mathrm{C}-\mathrm{SrIrO}_{3}$ because the former needs a smaller overpotential of $\sim 248 \mathrm{mV}$ to deliver a current density of $10 \mathrm{~mA} \mathrm{~cm}^{-2}$ geo. The superior catalytic activity of $6 \mathrm{H}-\mathrm{SrIrO}_{3}$ is further supported by the result that the former exhibits two times mass activity as high as the later (Fig. 3b).

Moreover, both $6 \mathrm{H}-\mathrm{SrIrO}_{3}$ and $3 \mathrm{C}-\mathrm{SrIrO}_{3}$ exhibit good catalytic stability for OER in acid, as shown in Fig. 3c. However, after 30 h-long electrocatalysis test, only $\sim 1 \%$ of total $\mathrm{Sr}$ content $\left(0.9-1.5 \mathrm{Sr}\right.$ layers of $\left.6 \mathrm{H}-\mathrm{SrIrO}_{3}\right)$ is detected in the acidic solution in the presence of $6 \mathrm{H}-\mathrm{SrIrO}_{3}$, whereas $\sim 24 \%$ of total $\mathrm{Sr}$ content is deviated from the stoichiometry of $3 \mathrm{C}-\mathrm{SrIrO}_{3}$ due to the $\mathrm{Sr}$ leaching during electrocatalysis (Fig. 3d). Considering that $3 \mathrm{C}-\mathrm{SrIrO}_{3}$ has been a Sr-deficient material with an $18 \%$ deviation before the electrocatalysis, the $3 \mathrm{C}-\mathrm{SrIrO}_{3}$ material after electrocatalysis has a total strontium deficiency up to $42 \%$. The result is also consistent with the $30-50 \%$ of total $\mathrm{Sr}$ content leaching for the thin films of $3 \mathrm{C}-\mathrm{SrIrO}_{3}$ as oxygen evolution catalysts in acid ${ }^{16}$. Additionally, HRTEM and X-ray photoelectron spectroscopy (XPS) results show that $6 \mathrm{H}$ $\mathrm{SrIrO}_{3}$ has good structural stability and keeps high crystallinity (Fig. $3 \mathrm{e}$ and Supplementary Figure 17), but $3 \mathrm{C}-\mathrm{SrIrO}_{3}$ takes place obvious surface amorphourization during electrocatalysis (Fig. 3f). This is further supported by the high-angle annular dark field (HAADF) STEM image (Supplementary Figure 20), which shows that there is not secondary, amorphous $\operatorname{IrO}_{\mathrm{x}}$ phase generated on the $6 \mathrm{H}-\mathrm{SrIrO}_{3}$ surface after OER. The $\mathrm{N}_{2}$ isotherm data of $6 \mathrm{H}-\mathrm{SrIrO}_{3}$ (Supplementary Figure 18) reveal that there are not micropores formed after OER. Moreover, the comparison of the $6 \mathrm{H}-\mathrm{SrIrO}_{3}$ 's $\mathrm{CV}$ curves before and after OER (Supplementary Figure 19) shows that the $\mathrm{CV}$ shape of $6 \mathrm{H}-\mathrm{SrIrO}_{3}$ after OER is not exactly same as that before OER, but does not change a lot. This suggests that $6 \mathrm{H}-\mathrm{SrIrO}_{3}$ might undergo a weak surface reconstruction during OER probably thanks to the slight Sr leaching during OER. It should be pointed out that while the better structural stability of $6 \mathrm{H}-\mathrm{SrIrO}_{3}$ than $3 \mathrm{C}-\mathrm{SrIrO}_{3}$ has been unambiguously confirmed, the possibility of a very thin amorphous $\mathrm{IrO}_{\mathrm{x}}$ layer (or a tiny amount of $\mathrm{IrO}_{\mathrm{x}}$ clusters) on the $6 \mathrm{H}-\mathrm{SrIrO}_{3}$ surface cannot be completely ruled out at current stage.

The better structural stability of $6 \mathrm{H}-\mathrm{SrIrO}_{3}$ in comparison with $3 \mathrm{C}-\mathrm{SrIrO}_{3}$ can be explained by the comparison of their $\mathrm{O}$ K-edge X-ray absorption spectra (Supplementary Figure 21). The comparison reveals that there is stronger Ir $5 d-\mathrm{O} 2 p$ hybridization or stronger $\mathrm{Ir}-\mathrm{O}$ covalence for $3 \mathrm{C}-\mathrm{SrIrO}_{3}$. The stronger covalence results in the easier structural loss of the perovskite phase or surface amorphourization during electrocatalysis, as suggested by the recent studies on perovskite electrocatalysts 33 .

In order to further assess the stability of $6 \mathrm{H}-\mathrm{SrIrO}_{3}$, we compared the Ir leaching during OER in the presence of $6 \mathrm{H}-\mathrm{SrIrO}_{3}$ and $\mathrm{IrO}_{2}$. We used inductively coupled plasma atomic emission spectroscopy (ICP-OES) to detect the Ir species in the electrolyte at a current density of $10 \mathrm{~mA} \mathrm{~cm}^{-2}$ geo with $6 \mathrm{H}-\mathrm{SrIrO}_{3}$ or $\mathrm{IrO}_{2}$ as the electrocatalyst. The result (Supplementary Figure 22) reveals that a tiny amount of leached 
Ir species are detected in the electrolytes for both $6 \mathrm{H}-\mathrm{SrIrO}_{3}$ and $\mathrm{IrO}_{2}$ as the electrocatalysts, but the amount of leached $\mathrm{Ir}$ species in the presence of $6 \mathrm{H}-\mathrm{SrIrO}_{3}$ as the electrocatalyst is obviously lower than that in the presence of $\mathrm{IrO}_{2}$ as the electrocatalyst. This result further demonstrates that $6 \mathrm{H}-\mathrm{SrIrO}_{3}$ is a stable electrocatalyst for OER in acid.

In order to determine the Faradaic efficiency during the OER, we compared the amount of $\mathrm{O}_{2}$ produced from the OER in the presence of $6 \mathrm{H}-\mathrm{SrIrO}_{3}$ with the theoretically expected $\mathrm{O}_{2}$ amount that can be generated from the OER. The result (Supplementary Figure 23) reveals that the detected $\mathrm{O}_{2}$ amount is very close to the expected value during the OER, further demonstrating the about $100 \%$ Faradaic efficiency given by $6 \mathrm{H}-\mathrm{SrIrO}_{3}$.

\section{Discussion}

We performed density functional theory (DFT) computations in order to get a better understanding of the electrocatalytic activity of $6 \mathrm{H}-\mathrm{SrIrO}_{3}$ for OER. We constructed the correlative theoretical models in view of the above experimental results, including the $\{001\}$ facet of $6 \mathrm{H}-\mathrm{SrIrO}_{3}$ as the main exposed one and a small amount of surface strontium leached during electrocatalysis. We cleaved the optimized $6 \mathrm{H}-\mathrm{SrIrO}_{3}$ bulk structure through its (001) plane to obtain two representative surfaces (Fig. $4 \mathrm{a}-\mathrm{d}$ ). The surface-I exposes the Ir atoms in the face-sharing octahedral dimers (Fig. 4a, b), while the surface-II exposes the Ir atoms in the isolated, corner-sharing $\mathrm{IrO}_{6}$ octahedra (Fig. 4c, d). On the basis of these surface models, we investigated the electrocatalytic activity for OER of $6 \mathrm{H}-\mathrm{SrIrO}_{3}$ according to the approach proposed by Rossmeisl et al. ${ }^{34,35}$ In this approach, the OER is suggested to include the four elementary reaction steps and each step involves one proton/one electron-coupled transfer process, as shown below:

$$
\begin{gathered}
\mathrm{H}_{2} \mathrm{O}+^{*} \rightarrow \mathrm{HO}^{*}+\mathrm{H}^{+}+e^{-} \\
\mathrm{HO}^{*} \rightarrow \mathrm{O}^{*}+\mathrm{H}^{+}+e^{-} \\
\mathrm{O}^{*}+\mathrm{H}_{2} \mathrm{O} \rightarrow \mathrm{HOO}^{*}+\mathrm{H}^{+}+e^{-} \\
\text {HOO }^{*} \rightarrow{ }^{*}+\mathrm{O}_{2}+\mathrm{H}^{+}+e^{-}
\end{gathered}
$$

where ${ }^{\star}$ and $\mathrm{X}^{\star}(\mathrm{X}=\mathrm{HO}, \mathrm{O}$, or $\mathrm{HOO})$ represent a surface active site and an adsorbed $\mathrm{X}$ intermediate on the surface, respectively.

As shown in Fig. $4 \mathrm{e}$ and $\mathrm{f}$, all of the four elementary reaction steps involved in the OER on both surface-I and surface-II are found to move uphill in free energy when no potential is applied $(U=0 \mathrm{~V})$. An additional potential has to be applied to make every step go downhill in free energy, and the minimum additional potentials are determined to be 1.69 and $1.80 \mathrm{~V}$ for the surface-I and surface-II, respectively. Considering the equilibrium potential of the OER $(U=1.23 \mathrm{~V})$, the minimum theoretical overpotentials $(\eta)$ are calculated to be 0.46 and $0.57 \mathrm{~V}$ for the surface-I and surface-II, respectively. These results further demonstrate that the surface-I, comprising the Ir atoms in the face-sharing octahedral dimers, has better catalytic activity for OER than the surface-II with the Ir atoms in the isolated, cornersharing $\mathrm{IrO}_{6}$ octahedra. For comparison, we also explore the OER activities on the (110) surface of $\mathrm{IrO}_{2}$ and (010) surface of 3C$\mathrm{SrIrO}_{3}$, and both the sampled surfaces have the similar structural feature to the surface-II, as illustrated in Supplementary Figures 24 and 25. Our computed overpotentials are 0.59 and $0.56 \mathrm{~V}$ for $\mathrm{IrO}_{2}$ and $3 \mathrm{C}$-SrIrO 3 , respectively, both of which are
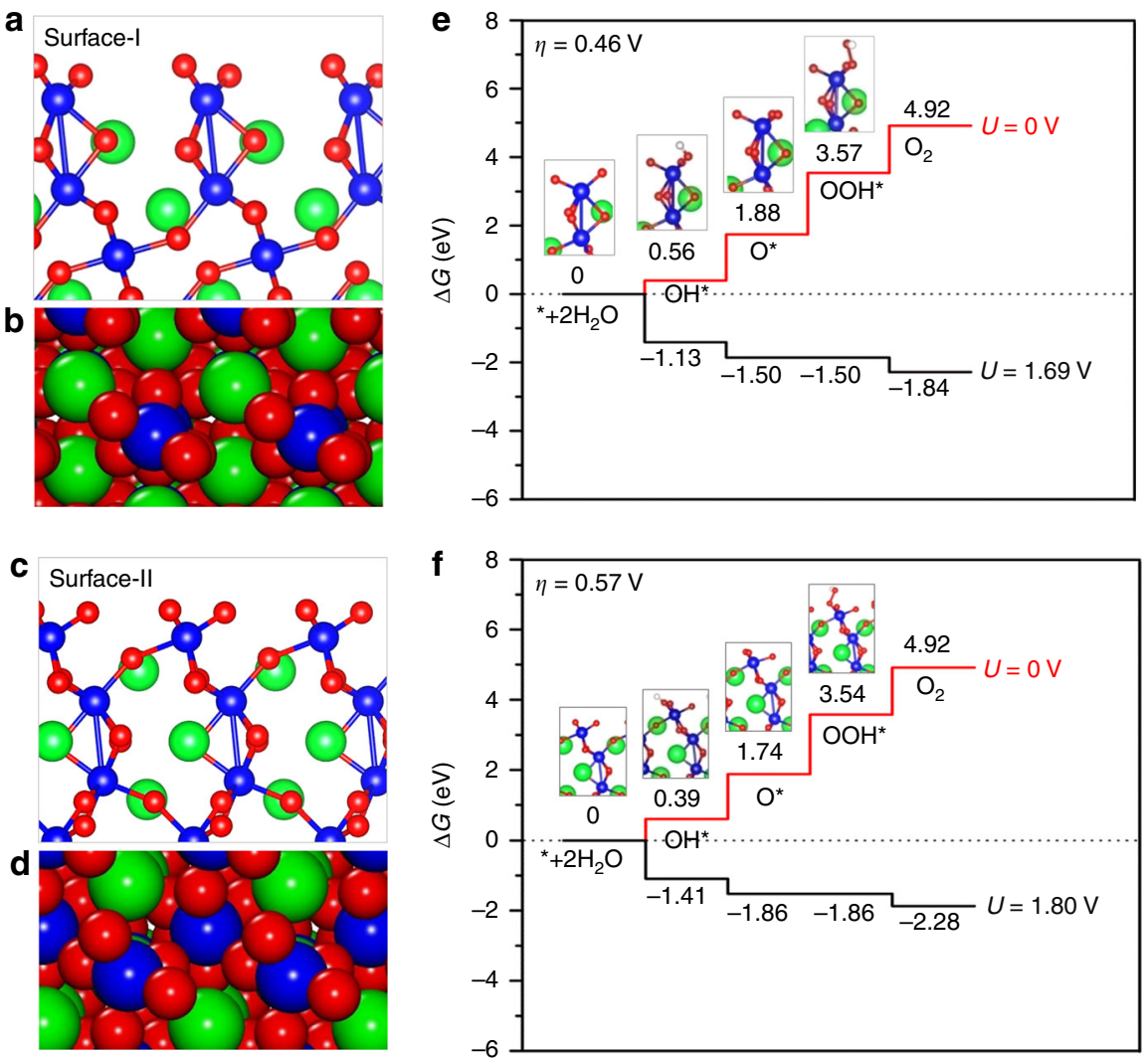

Fig. 4 Theoretical understanding of electrocatalytic activity for OER of $6 \mathrm{H}-\mathrm{SrlrO}_{3}$. a Side and $\mathbf{b}$ top views of the surface-I of $6 \mathrm{H}-\mathrm{SrlrO} \mathrm{O}_{3}$; $\mathbf{S i d e}$ and $\mathbf{d}$ top views of the surface- $I I$ of $6 \mathrm{H}-\mathrm{SrlrO}_{3}$; free-energy diagrams of four elementary reaction steps for the OER on $\mathbf{e}$ the surface-I and $\mathbf{f}$ surface-ll of $6 \mathrm{H}-\mathrm{SrlrO} \mathrm{O}_{3}$ at the different applied potentials. The optimized structures of $\mathrm{HO}, \mathrm{O}$, and $\mathrm{HOO}$ adsorptions on the surface-I and surface-II are also shown in $\mathbf{e}$ and $\mathbf{f}$ 
comparable to that of the surface-II $(0.57 \mathrm{~V})$ and larger than that of surface-I $(0.46 \mathrm{~V})$. It is worth mentioning that our computed overpotential on the (110) surface of $\mathrm{IrO}_{2}$ is also close to the previously reported one ${ }^{34}$. The above calculations imply that the existence of face-sharing octahedral dimers (the main structural feature of surface-I) is mainly responsible for the superior OER activity of $6 \mathrm{H}-\mathrm{SrIrO}_{3}$, as observed in the above experimental results.

From the Fig. 4e and f, we can also find that the potentialdetermining step for both surface-I and surface-II is the third elementary reaction step involved in the OER (i.e., $\mathrm{O}^{*}+\mathrm{H}_{2} \mathrm{O} \rightarrow$ $\mathrm{HOO}^{*}+\mathrm{H}^{+}+e$-) because the maximum Gibbs free-energy difference is between $\Delta G_{\mathrm{HOO}^{*}}$ and $\Delta G_{\mathrm{O}^{*}}$. The facilitated potentialdetermining step involved in the OER for the surface-I, with respect to the surface-II, can be attributed to the relatively weak $\mathrm{O}$ binding (or the relatively low ability of Ir atoms to bind oxygen) on the surface-I, because the surface-I binds oxygen with an $\mathrm{O}^{*}$ binding energy of $1.848 \mathrm{eV}$, while the surface-II binds $\mathrm{O}^{*}$ more strongly $\left(\Delta E_{\mathrm{O}^{*}}=1.711 \mathrm{eV}\right)$.

When DFT calculations have provided some useful insights into the catalytic active sites and the activity trend for the Ir-based materials from the theoretical computations is consistent with that from our experiments, there is difference between the thermodynamic overpotentials obtained by DFT and the experimental ones. This difference might be caused by multiple factors. First, all the computations are based on thermodynamic considerations. Other important electrocatalytic processes, such as mass and charge transport, cannot be involved in the DFT calculations. Second, the distribution and concentration of active sites on the real material surface are generally very complex, but this complexity cannot be adequately reflected by DFT calculations. Third, at current stage, DFT calculations are not capable of providing atomic information on the more complex catalystelectrolyte interface, which is crucially important for the electrocatalysis process.

In summary, $6 \mathrm{H}-\mathrm{SrIrO}_{3}$ has been identified as a highly efficient, low-iridium oxygen evolution electrocatalyst that can work well in acidic media. $6 \mathrm{H}-\mathrm{SrIrO}_{3}$ is an unusual perovskite oxide electrocatalyst with face-sharing $\mathrm{IrO}_{6}$ octahedral dimers. The unique face-sharing $\mathrm{IrO}_{6}$ octahedral subunits of $6 \mathrm{H}-\mathrm{SrIrO}_{3}$ are proven to be important for its remarkable catalytic activity and structural stability. These good properties also make $6 \mathrm{H}-\mathrm{SrIrO}_{3}$ a promising electrocatalyst for proton exchange membrane (PEM) water electrolysis. The findings in this work might help spark a kind of creativity in the rational design/synthesis of highperformance electrocatalysts for the acidic OER.

\section{Methods \\ Chemicals and reagents. Potassium hexachloroiridate(IV) $\left(\mathrm{K}_{2} \mathrm{IrCl}_{6}, 99.99 \%\right)$ was purchased from Aladdin. Strontium nitrate $\left(\mathrm{Sr}\left(\mathrm{NO}_{3}\right)_{2}\right)$, citric acid monohydrate $\left(\mathrm{C}_{6} \mathrm{H}_{8} \mathrm{O}_{7} \cdot \mathrm{H}_{2} \mathrm{O}\right)$, ethylene glycol, hydrochloric acid $(\mathrm{HCl})$ and sulfuric acid $\left(\mathrm{H}_{2} \mathrm{SO}_{4}\right)$ were purchased from Beijing Chemical Factory. Cobalt nitrate hexahydrate (Co $\left.\left(\mathrm{NO}_{3}\right)_{2} \cdot 6 \mathrm{H}_{2} \mathrm{O}\right)$ was purchased from Shantou Xilong Chemical Factory. Nafion ${ }^{\circledR}$ perfluorinated resin solution (5 wt.\% in mixture of lower aliphatic alcohols and water containing $45 \%$ water) was purchased from Sigma-Aldrich. All the chemicals and reagents were used without further purification. Highly purified water $(>18$ $\mathrm{M} \Omega \mathrm{cm}$ resistivity) was provided by a PALL PURELAB Plus system.}

Materials synthesis. For the synthesis of $6 \mathrm{H}-\mathrm{SrIrO}_{3}, \mathrm{Sr}\left(\mathrm{NO}_{3}\right)_{2}(280 \mathrm{mg})$ and citric acid $\left(280 \mathrm{mg}\right.$ ) were mixed with $5 \mathrm{~mL}$ deionized $\mathrm{H}_{2} \mathrm{O}$ to form the solution 1 , and $\mathrm{K}_{2} \mathrm{IrCl}_{6}(80 \mathrm{mg}$ ) was mixed with $4 \mathrm{~mL}$ ethylene glycol to form the solution 2 . The solution 1 was then stirred into the solution 2 dropwise. The resulting mixture was dried at $150^{\circ} \mathrm{C}$ for $12 \mathrm{~h}$ to obtain a brown solid product as the precursor, followed by calcination in air at $200{ }^{\circ} \mathrm{C}(6 \mathrm{~h}), 300{ }^{\circ} \mathrm{C}(6 \mathrm{~h}), 500^{\circ} \mathrm{C}(3 \mathrm{~h})$, and $700{ }^{\circ} \mathrm{C}(6 \mathrm{~h})$ in succession. The heating rate was $1.7^{\circ} \mathrm{C} \mathrm{min}-1$. The obtained solid product containing $\mathrm{SrIrO}_{3}$ and $\mathrm{SrCO}_{3}$ was treated with $1 \mathrm{M} \mathrm{HCl}$ for $6 \mathrm{~h}$ to remove the $\mathrm{SrCO}_{3}$ impurities, giving the $6 \mathrm{H}-\mathrm{SrIrO}_{3}$ material. The sequence of synthesis steps was refined through trials and errors.

In order to further assess the stability of $6 \mathrm{H}-\mathrm{SrIrO}_{3}$ in $1 \mathrm{M} \mathrm{HCl}$ solution, we dispersed the as-obtained $6 \mathrm{H}-\mathrm{SrIrO}_{3}$ powders in $1 \mathrm{M} \mathrm{HCl}$ solution for 2 days, and then used ICP-OES to detect the Sr and Ir ions in the solution. The result shows that there is no detectable leached $\mathrm{Sr}$ and $\mathrm{Ir}$ species in the solution, demonstrating the good stability of $6 \mathrm{H}-\mathrm{SrIrO}_{3}$ in $1 \mathrm{M} \mathrm{HCl}$ solution.

For the synthesis of $3 \mathrm{C}$-SrIrO${ }_{3}$, the experimental procedures are almost the same as these for the synthesis of $6 \mathrm{H}-\mathrm{SrIrO}_{3}$, except the amount of citric acid (840 $\mathrm{mg}$ ) that was used to form the solution 1.

For the synthesis of Co-doped $3 \mathrm{C}-\mathrm{SrIrO}_{3}$ as a control sample, the experimental procedures are almost the same as these for the synthesis of $6 \mathrm{H}-\mathrm{SrIrO}_{3}$. The only difference was that a certain amount of cobalt nitrate hexahydrate $(14.5 \mathrm{mg})$ was added to form the solution 2. In the resulting sample, labeled as Co-doped 3C$\mathrm{SrIrO}_{3}$, the Co:Ir atomic ratio is about 1:4.

In order to synthesize the $\mathrm{SrIrO}_{3}$ phases $\left(6 \mathrm{H}-\mathrm{SrIrO}_{3}\right.$ and $\left.3 \mathrm{C}-\mathrm{SrIrO}_{3}\right)$ without $\mathrm{IrO}_{2}$ as the secondary phase, an excessive amount of strontium ( $\mathrm{Sr}: \mathrm{Ir}$ atomic ratio $=8: 1$ ) was used during the synthesis in this work. The use of the excessive amount of strontium resulted in the formation of strontium carbonates $\left(\mathrm{SrCO}_{3}\right)$ as the impurities (please see Supplementary Figure 26). The acid treatment with $1 \mathrm{M} \mathrm{HCl}$ was employed to remove the $\mathrm{SrCO}_{3}$ impurities.

For the synthesis of $\mathrm{IrO}_{2}$, the experimental procedures are almost the same as these for the synthesis of $6 \mathrm{H}$-SrIrO $\mathrm{S}_{3}$. The only difference was that $\mathrm{Sr}\left(\mathrm{NO}_{3}\right)_{2}$ was not involved in the synthesis. Supplementary Figure 27 presents XRD patterns of the $\mathrm{IrO}_{2}$ samples obtained by calcining the precursor at 300,500 , and $700{ }^{\circ} \mathrm{C}$.

Characterizations. Powder X-ray diffraction patterns (PXRD) of the samples were collected with an X-ray diffractometer (RIGAKU, Japan, model D/MAX2550 V/ PC) with a scan speed of $1^{\circ} \mathrm{min}^{-1}$ within the diffraction angle range from 10 to $140^{\circ}$. Profile fitting for the PXRD pattern was performed with general structure analysis system (GSAS) program. The scanning electron microscope (SEM) images were obtained with a JEOL JSM 6700F electron microscope. The transmission electron microscope (TEM) images were obtained with a Philips-FEI Tecnai G2S Twin microscope equipped with a field emission gun operating at $200 \mathrm{kV}$. Inductively coupled plasma atomic emission spectroscopy (ICP-OES) was performed on a Perkin-Elmer Optima 3300DV ICP spectrometer. The X-ray photoelectron spectroscopy (XPS) was performed on an ESCALAB 250X-ray photoelectron spectrometer with a monochromatic X-ray source (Al K $\alpha h v=$ $1486.6 \mathrm{eV}$ ). The O K-edge X-ray absorption near-edge (XANES) spectra were measured in the total electron yield mode in a vacuum chamber $\left(<5 \times 10^{-8} \mathrm{~Pa}\right)$. This measurement was performed at the BL12B-a beamline of National Synchrotron Radiation Laboratory (NSRL) in China. The electrical resistivity was investigated with Van Der Pauw method, and the measurement was conducted in a Physical Property Measurement System (PPMS, Quantum Design). High-angle annular dark field scanning transmission electron microscopy (STEM) images were acquired using an aberration-corrected STEM with the model of FEI Titan Cubed Themis G2 300, whose accelerating voltage and electron current were set at $200 \mathrm{kV}$ and around $40 \mathrm{pA}$, respectively. (Note that because $6 \mathrm{H}-\mathrm{SrIrO}_{3}$ is very sensitive to the electron beams, high-angle annular dark field STEM images must be obtained at the lowest electron current of $40 \mathrm{pA}$ ).

Electrochemical measurements. All the electrochemical measurements were performed with a three-electrode system by using a CHI instrument (Model 650E). The electrolyte was $0.5 \mathrm{M} \mathrm{H}_{2} \mathrm{SO}_{4}$, and was bubbled with $\mathrm{O}_{2}$ gas during the electrochemical measurements. A carbon rod was used as the counter electrode, and a saturated calomel electrode (SCE) was used as the reference electrode. The saturated calomel electrode was calibrated by the reversible hydrogen electrode (RHE), giving their conversion equation: $E_{\mathrm{vs} . \mathrm{RHE}}=E_{\mathrm{vs} . \mathrm{SCE}}+0.241 \mathrm{~V}$. The scan rate was 0.5 $\mathrm{mV} \mathrm{s}{ }^{-1}$ when linear sweep voltammetry (LSV) was used. The data in this work were compensated by $85 \%$ iR-drop. The geometric surface area of the electrode was used to normalize the current density.

For the preparation of working electrodes, the powdered catalyst $(7 \mathrm{mg})$, including $6 \mathrm{H}-\mathrm{SrIrO}_{3}, 3 \mathrm{C}$-SrIrO 3 , and $\mathrm{IrO}_{2}$, was dispersed in a mixture comprising isopropanol $(100 \mu \mathrm{L})$ and Nafion solution $(10 \mu \mathrm{L}, 5$ wt.\% in mixture of lower aliphatic alcohols and water). $1 \mu \mathrm{L}$ of the resulting mixture was then drop-casted onto a glassy carbon electrode with a diameter of $3 \mathrm{~mm}$ for drying. The working electrode had a catalyst loading of ca. $0.90 \mathrm{mg} \mathrm{cm}^{-2}$.

The electrochemically active surface area (ECSA) of each sample was obtained by determining the double-layer capacitance at non-Faradaic potential range, according to the method reported by Jaramillo et al. ${ }^{36} \mathrm{~A}$ series of cyclic voltammetry $(\mathrm{CV})$ measurements were performed first at various scan rates $(10,25$, 50,75 and $100 \mathrm{mV} \mathrm{s}^{-1}$ ) in the potential window between 0.83 and $0.93 \mathrm{~V}$ vs. RHE Then, a linear plot was obtained by establishing the relationship between the difference of the anodic and cathodic currents $\left(i_{\mathrm{a}}-i_{\mathrm{c}}\right)$ at $0.88 \mathrm{~V}$ vs. RHE and the scan rate. The double-layer capacitance $\left(C_{\mathrm{dl}}\right)$ is one half of the slope value of the fitting line. The ECAS can be obtained by dividing $C_{\mathrm{dl}}$ by a specific capacitance $\left(C_{\mathrm{s}}\right)$. A $C_{\mathrm{s}}$ value of $0.035 \mathrm{mF} \mathrm{cm} \mathrm{cm}^{-2}$ was suggested in the previously reported work 36 .

The reference electrode (i.e., saturated calomel electrode, SCE) was calibrated by the reversible hydrogen electrode (RHE) in $0.5 \mathrm{M} \mathrm{H}_{2} \mathrm{SO}_{4}$. Two Pt electrodes were first cleaned by cycled in $0.5 \mathrm{M} \mathrm{H}_{2} \mathrm{SO}_{4}$ between -2 and $2 \mathrm{~V}$ for $2 \mathrm{~h}$, and then used as the working electrode and the counter electrode, respectively. During the calibration, the electrolyte was saturated by $\mathrm{H}_{2}$. A series of controlled-potential chronoamperometric curves were carried out around the possible zero current potential (the interconversion between the hydrogen oxidation and hydrogen 
evolution reaction) with a dwell time of $5 \mathrm{~min}$. The result showed that the potential of zero net current was found at $-0.241 \mathrm{~V}$ vs. the SCE electrode. And thus, the potentials, measured against SCE, were converted into the potentials vs. RHE by using the equation: $E_{\mathrm{vs} . \mathrm{RHE}}=E_{\mathrm{vs} . \mathrm{SCE}}+0.241 \mathrm{~V}$.

Computation details. The generalized gradient approximation (GGA) with the Perdew-Burke-Ernzerhof exchange-correlation functional ${ }^{37}$ (including a semiempirical van der Waals (vdW) correction to account for the dispersion interactions $)^{38,39}$ and a $400-\mathrm{eV}$ cutoff for the plane-wave basis set are employed to perform all the density functional theory (DFT) computations within the frame of Vienna ab initio simulation package (VASP) ${ }^{40,41}$. The projector-augmented plane wave (PAW) is used to describe the electron-ion interactions ${ }^{42,43} .5 \times 3 \times 2$ and $5 \times$ $5 \times 1$ Monkhorst-Pack grid $k$-points are employed for geometric optimization of $6 \mathrm{H}-\mathrm{SrIrO}_{3}$ and the corresponding slab surfaces, respectively. The density of state (DOS) of the $6 \mathrm{H}-\mathrm{SrIrO}_{3}$ is computed by using $77 k$-points. The convergence threshold is set as $10^{-4} \mathrm{eV}$ in energy and $0.05 \mathrm{eV} / \AA$ in force. For all the calculations of slab models, the symmetrization is switched off and the dipolar correction is included. Our computed lattice parameters for $6 \mathrm{H}-\mathrm{SrIrO}_{3}$ are about $a=5.554, b=$ 9.584, and $c=14.024 \AA$, all of which are in good agreement with their corresponding experimental values 28 .

The free energy of $\mathrm{H}^{+}+e$ - can be half of formation energy of $\mathrm{H}_{2}$ at $298 \mathrm{~K}$ and $1 \mathrm{~atm}$. The free energy of the OER is computed by the equation $\Delta G=\Delta E+\Delta \mathrm{ZP} E-$ $T \Delta S$. The value of $\Delta E$ is obtained by the computation of geometrical structures. The values of $\triangle \mathrm{ZPE}$ and $\triangle S$ are determined by employing the computed vibrational frequencies and standard tables for the reactants and products in the gas phase ${ }^{44}$ The entropy for the adsorbed atoms/molecules at the surface active site are assumed to be zero. The temperature dependence of the enthalpy is neglected in the calculations. Moreover, an external bias $U$ is imposed on each step by including $a-e U$ term in the computation of reaction free energy. Consequently, the reaction free energy of each step can be expressed as follows:

$$
\begin{gathered}
\Delta G_{1}=E\left(\mathrm{HO}^{*}\right)-E\left(^{*}\right)-E_{\mathrm{H} 2 \mathrm{O}+} 1 / 2 E_{\mathrm{H} 2}+(\Delta \mathrm{ZPE}-T \Delta S)_{\mathrm{A}}-e U \\
\Delta G_{2}=E\left(\mathrm{O}^{*}\right)-E\left(\mathrm{HO}^{*}\right)+1 / 2 E_{\mathrm{H} 2}+(\Delta \mathrm{ZPE}-T \Delta S)_{\mathrm{B}}-e U \\
\Delta G_{3}=E\left(\mathrm{HOO}^{*}\right)-E\left(\mathrm{O}^{*}\right)-E_{\mathrm{H} 2 \mathrm{O}}+1 / 2 E_{\mathrm{H} 2}+(\Delta \mathrm{ZPE}-T \Delta S)_{\mathrm{C}}-e U \\
\Delta G_{4}=E\left(^{*}\right)-E\left(\mathrm{HOO}^{*}\right)+E_{\mathrm{O} 2}+1 / 2 E_{\mathrm{H} 2}+(\Delta \mathrm{ZPE}-T \Delta S)_{\mathrm{D}}-e U
\end{gathered}
$$

where $E\left(^{*}\right), E\left(\mathrm{HO}^{*}\right), E\left(\mathrm{O}^{*}\right)$, and $E\left(\mathrm{HOO}^{*}\right)$ are the computed DFT energies of the pure surface and the adsorbed surfaces with $\mathrm{HO}^{*}, \mathrm{O}^{*}$, and $\mathrm{HOO}^{*}$, respectively. $E_{\mathrm{H} 2 \mathrm{O}}, E_{\mathrm{H} 2}$, and $E_{\mathrm{O} 2}$ are the computed energies for the sole $\mathrm{H}_{2} \mathrm{O}, \mathrm{H}_{2}$ and $\mathrm{O}_{2}$ molecules, respectively. For the total reaction $\mathrm{H}_{2} \mathrm{O} \rightarrow 1 / 2 \mathrm{O}_{2}+\mathrm{H}_{2}$, the free-energy change is fixed at the experimental value of $2.46 \mathrm{eV}$ per water molecule. When forming one molecule of $\mathrm{O}_{2}$ in the reaction step, the reaction free energy can be expressed as $\Delta G_{(2 \mathrm{H} 2 \mathrm{O} \rightarrow \mathrm{O} 2+2 \mathrm{H} 2)}=4.92 \mathrm{eV}=E_{\mathrm{O} 2}+2 E_{\mathrm{H} 2}-2 E_{\mathrm{H} 2 \mathrm{O}}+(\Delta \mathrm{ZPE}-$ $T \Delta S)_{(2 \mathrm{H} 2 \mathrm{O} \rightarrow \mathrm{O} 2+2 \mathrm{H} 2)}$. The reaction overpotential can be obtained by evaluating the difference between the minimum voltage needed for the OER and the corresponding voltage needed for changing all the free-energy steps into downhill. The correlative theoretical models are constructed based on the experimental results, including the $\{001\}$ facet of $6 \mathrm{H}-\mathrm{SrIrO}_{3}$ as the main exposed one and a small amount of surface strontium leached during electrocatalysis. The dissolution of $\mathrm{SrIrO}_{3}$ to form Sr${ }^{2+}$ can be written as $\mathrm{SrIrO}_{3}+2 \mathrm{H}^{+} \rightarrow \mathrm{IrO}_{2}+\mathrm{Sr}^{2+}+\mathrm{H}_{2} \mathrm{O}$, and in this situation, $\mathrm{Sr}$ atoms and the related $\mathrm{O}$ atoms in the uppest layer for these structural models are discarded from a stoichiometric $\mathrm{SrIrO}_{3}(001)$ surface. All the theoretical models have the thickness of six layers. During the computational process, the upper two layers in the model are fully relaxed without any symmetry or directional restrictions, while the remaining four layers are kept frozen.

The ELF was extensively employed to understand the localized bonding character in the crystal structures ${ }^{26,27}$. The ELF can be described in the form of a contour plot in real space with values ranging from 0 to 1 . The region close to 1 indicates the presence of strong covalent electrons or lone-pair electrons. While the region near to 0.5 represents homogenous electron gas or the presence of metallic bonds, the region close to 0 means a low electron density area. The ELF is different from the molecular orbital theory that can display the orbital orientation. In our work, we employed the ELF method to confirm the existence of Ir-Ir metallic bond in the face-shared $\mathrm{IrO}_{6}$ dimers. As presented in Fig. 1d, the correlative ELF values with a range of 0.4 to 0.5 distribute between the two neighboring Ir atoms in facesharing $\mathrm{IrO}_{6}$ dimers, indicating that $\mathrm{Ir}-\mathrm{Ir}$ bond is metallic in character.

\section{Data availability}

The authors declare that the data supporting the findings of this study are available within the paper and its supplementary information files.

Received: 15 April 2018 Accepted: 14 November 2018

Published online: 07 December 2018

\section{References}

1. Cook, T. R. et al. Solar energy supply and storage for the legacy and nonlegacy worlds. Chem. Rev. 110, 6474-6502 (2010).

2. Seh, Z. W. et al. Combining theory and experiment in electrocatalysis: insights into materials design. Science 355, eaad4998 (2017).

3. Zou, X. \& Zhang, Y. Noble metal-free hydrogen evolution catalysts for water splitting. Chem. Soc. Rev. 44, 5148-5180 (2015).

4. Feng, J. et al. Iridium-based multimetallic porous hollow nanocrystals for efficient overall-water-splitting catalysis. Adv. Mater. 29, 1703798 (2017).

5. Pi, Y., Shao, Q., Wang, P., Guo, J. \& Huang, X. General formation of monodisperse IrM $(\mathrm{M}=\mathrm{Ni}, \mathrm{Co}, \mathrm{Fe})$ bimetallic nanoclusters as bifunctional electrocatalysts for acidic overall water splitting. Adv. Funct. Mater. 27, 1700886 (2017).

6. Stevens, M. B. et al. Measurement techniques for the study of thin film heterogeneous water oxidation electrocatalysts. Chem. Mater. 29, 120-140 (2017).

7. Smith, R. D. L. et al. Photochemical route for accessing amorphous metal oxide materials for water oxidation catalysis. Science 340, 60-63 (2013).

8. Zhang, B. et al. Homogeneously dispersed, multimetal oxygen-evolving catalysts. Science 352, 333-337 (2016).

9. Gong, M. et al. An advanced Ni-Fe layered double hydroxide electrocatalyst for water oxidation. J. Am. Chem. Soc. 135, 8452-8455 (2013).

10. Suntivich, J., May, K. J., Gasteiger, H. A., Goodenough, J. B. \& Shao-Horn, Y A perovskite oxide optimized for oxygen evolution catalysis from molecular orbital principles. Science 334, 1383-1385 (2011).

11. Zou, X., Goswami, A. \& Asefa, T. Efficient noble metal-free (electro)catalysis of water and alcohol oxidations by zinc-cobalt layered double hydroxide. $J$. Am. Chem. Soc. 135, 17242-17245 (2013).

12. Zhu, Y. P., Ma, T. Y., Jaroniec, M. \& Qiao, S. Z. Self-templating synthesis of hollow $\mathrm{Co}_{3} \mathrm{O}_{4}$ microtube arrays for highly efficient water electrolysis. Angew. Chem. Int. Ed. 56, 1324-1328 (2017).

13. Jia, Y. et al. A heterostructure coupling of exfoliated $\mathrm{Ni}-\mathrm{Fe}$ hydroxide nanosheet and defective graphene as a bifunctional electrocatalyst for overall water splitting. Adv. Mater. 29, 1700017 (2017).

14. Kim, J. et al. High-performance pyrochlore-type yttrium ruthenate electrocatalyst for oxygen evolution reaction in acidic media. J. Am. Chem. Soc. 139, 12076-12083 (2017).

15. Diaz-Morales, O. et al. Iridium-based double perovskites for efficient water oxidation in acid media. Nat. Commun. 7, 12363 (2016).

16. Seitz, L. C. et al. A highly active and stable $\mathrm{IrO}_{\mathrm{x}} / \mathrm{SrIrO}_{3}$ catalyst for the oxygen evolution reaction. Science 353, 1011-1014 (2016).

17. Grimaud, A. et al. Activation of surface oxygen sites on an iridium-based model catalyst for the oxygen evolution reaction. Nat. Energy 2, 16189 (2016).

18. Sardar, K. et al. Water-splitting electrocatalysis in acid conditions using ruthenate-iridate pyrochlores. Angew. Chem. Int. Ed. 53, 10960-10964 (2014)

19. Sun, W. et al. OER activity manipulated by $\mathrm{IrO}_{6}$ coordination geometry: an insight from pyrochlore iridates. Sci. Rep. 6, 38429 (2016).

20. Sardar, K. et al. Bismuth iridium oxide oxygen evolution catalyst from hydrothermal synthesis. Chem. Mater. 24, 4192-4200 (2012).

21. Lebedev, D. et al. Highly active and stable iridium pyrochlores for oxygen evolution reaction. Chem. Mater. 29, 5182-5191 (2017).

22. Kumari, S. et al. A low-noble-metal $\mathrm{W}_{1-\mathrm{x}} \mathrm{Ir}_{\mathrm{x}} \mathrm{O}_{3-\delta}$ water oxidation electrocatalyst for acidic media via rapid plasma synthesis. Energy Environ. Sci. 10, 2432-2440 (2017).

23. Huynh, M., Ozel, T., Liu, C., Lau, E. C. \& Nocera, D. G. Design of templatestabilized active and earth-abundant oxygen evolution catalysts in acid. Chem. Sci. 8, 4779-4794 (2017).

24. Carmo, M., Fritz, D. L., Merge, J. \& Stolten, D. A comprehensive review on PEM water electrolysis. Int. J. Hydrog. Energ. 38, 4901-4934 (2013).

25. Longo, J., Kafalas, J. \& Arnott, R. Structure and properties of the high and low pressure forms of $\mathrm{SrIrO}_{3}$. J. Solid State Chem. 3, 174-179 (1971).

26. Savin, A., Jepsen, J., Andersen, O. K., Preuss, H. \& von Schnering, H. G. Electron localization in solid-state structures of the elements: the diamond structure. Angew. Chem. Int. Ed. 31, 187-188 (1992).

27. Chen, Y. et al. Highly active, nonprecious electrocatalyst comprising borophene subunits for the hydrogen evolution reaction. J. Am. Chem. Soc. 139, 12370-12373 (2017).

28. Qasim, I., Kennedy, B. J. \& Avdeev, M. Synthesis, structures and properties of transition metal doped $\mathrm{SrIrO}_{3}$. J. Mater. Chem. A 1, 3127-3132 (2013).

29. Kronbo, C. H. et al. High pressure structure studies of $6 \mathrm{H}-\mathrm{SrIrO}_{3}$ and the octahedral tilting in $3 \mathrm{C}-\mathrm{SrIrO}_{3}$ towards A post-perovskite. J. Solid State Chem. 238, 74-82 (2016)

30. Sanchez Casalongue, H. G. et al. In situ observation of surface species on iridium oxide nanoparticles during the oxygen evolution reaction. Angew. Chem. Int. Ed. 53, 7169-7172 (2014).

31. Bremholm, M. et al. Destabilization of the $6 \mathrm{H}-\mathrm{SrIrO}_{3}$ polymorph through partial substitution of zinc and lithium. J. Mater. Chem. 22, 16431-16436 (2012). 
32. Qasim, I., Kennedy, B. J. \& Avdeev, M. Stabilising the orthorhombic perovskite structure in $\mathrm{SrIrO}_{3}$ through chemical doping. Synthesis, structure and magnetic properties of $\operatorname{SrIr}_{1-\mathrm{x}} \mathrm{Mg}_{\mathrm{x}} \mathrm{O}_{3}(0.20 \leq \mathrm{x} \leq 0.33)$. J. Mater. Chem. A 1, 13357-13362 (2013)

33. Hwang, J. et al. Perovskites in catalysis and electrocatalysis. Science 358, 751-756 (2017).

34. Rossmeisl, J., Qu, Z.-W., Zhu, H., Kroes, G.-J. \& Nørskov, J. K. Electrolysis of water on oxide surfaces. J. Electroanal. Chem. 607, 83-89 (2007).

35. Man, I. C. et al. Universality in oxygen evolution electrocatalysis on oxide surfaces. ChemCatChem 3, 1159-1165 (2011).

36. McCrory, C. C. L. et al. Benchmarking hydrogen evolving reaction and oxygen evolving reaction electrocatalysts for solar water splitting devices. J. Am. Chem. Soc. 137, 4347-4357 (2015).

37. Perdew, J. P., Burke, K. \& Ernzerhof, M. Generalized gradient approximation made simple. Phys. Rev. Lett. 77, 3865-3868 (1996).

38. Grimme, S. Semiempirical GGA-type density functional constructed with a long-range dispersion correction. J. Comput. Chem. 27, 1787-1799 (2006).

39. Wu, X., Vargas, M. C., Nayak, S., Lotrich, V. \& Scoles, G. Towards extending the applicability of density functional theory to weakly bound systems. J. Chem. Phys. 115, 87488757 (2001).

40. Kresse, G. \& Hafner, J. Ab initio molecular dynamics for liquid metals. Phys. Rev. B 47, 558-561 (1993).

41. Kresse, G. \& Hafner, J. Ab-initio molecular-dynamics simulation of the liquidmetal amorphous-semiconductor transition in germanium. Phys. Rev. B 49, 14251-14269 (1994)

42. Blöchl, P. E. Projector augmented-wave method. Phys. Rev. B 50, 17953-17979 (1994).

43. Kresse, G. \& Joubert, D. From ultrasoft pseudopotentials to the projector augmented-wave method. Phys. Rev. B 59, 1758-1775 (1999).

44. Valdés, A., Qu, Z.-W., Kroes, G.-J., Rossmeisl, J. \& Nørskov, J. K. Oxidation and photo-oxidation of water on $\mathrm{TiO}_{2}$ surface. J. Phys. Chem. C. 112, 9872-9879 (2008).

\section{Acknowledgements}

This work is financially supported by the National Natural Science Foundation of China (NSFC, Grant Nos. 21771079, 21673094, 21673093, and 21573090), National Key R\&D Program of China, Grant No. 2017YFA0207800, Jilin Province Science and Technology Development Plan 20170101141JC and 20170101175JC, Program for JLU Science and Technology Innovative Research Team (JLUSTIRT), Fok Ying Tung Education Foundation, Grant No. 161011 and Science and Technology Research Program of Education Department of Jilin Province (JJKH20170780KJ). We thank the NSRL beamline BL12B-a of National Synchrotron Radiation Laboratory for the XAS measurement, Center for
Electron Microscopy in Tianjin University of Technology, and the Computing Center of Jilin Province for the supercomputer time. We thank the National Natural Science Foundation of China (Grant No. 21621001) and the 111 Project (No.B17020) for financial support.

\section{Author contributions}

X.Z. conceived the idea, organized the data, and wrote the manuscript. G.Y. and W.C. performed the theoretical computations and analyzed the theoretical results. L.Y. synthesized the materials and studied their electrochemical properties. X.A., X.L., and J.-S.C. assisted L.Y. with the materials synthesis and the analysis of crystal structure. W.Y. and H.D. performed the XAS measurement. T.W., C.Z., and X.H. assisted W.C. with DFT calculations. All of the authors have read the manuscript and agree with its content.

\section{Additional information}

Supplementary Information accompanies this paper at https://doi.org/10.1038/s41467018-07678-w.

\section{Competing interests: The authors declare no competing interests.}

Reprints and permission information is available online at http://npg.nature.com/ reprintsandpermissions/

Publisher's note: Springer Nature remains neutral with regard to jurisdictional claims in published maps and institutional affiliations.

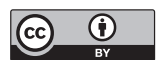

Open Access This article is licensed under a Creative Commons Attribution 4.0 International License, which permits use, sharing, adaptation, distribution and reproduction in any medium or format, as long as you give appropriate credit to the original author(s) and the source, provide a link to the Creative Commons license, and indicate if changes were made. The images or other third party material in this article are included in the article's Creative Commons license, unless indicated otherwise in a credit line to the material. If material is not included in the article's Creative Commons license and your intended use is not permitted by statutory regulation or exceeds the permitted use, you will need to obtain permission directly from the copyright holder. To view a copy of this license, visit http://creativecommons.org/ licenses/by/4.0/.

(C) The Author(s) 2018 